well within our previously reported range of values for schizophrenic patients responding to typical antipsychotics $(n=10 ; \mathrm{LBG} / \mathrm{FC}=1.29 \pm 0.048, \mathrm{RBG} / \mathrm{FC}=1.24 \pm 0.045)$, and is clearly lower than those obtained in either nonmedicated $(n=20 ; \quad \mathrm{LBG} / \mathrm{FC}=1.71 \pm 0.027, \mathrm{RBG} / \mathrm{FC}=$ $1.65 \pm 0.024)$ or clozapine-treated patients $(n=10 ; \mathrm{LBG} /$ $\mathrm{FC}=1.48 \pm 0.038, \mathrm{RBG} / \mathrm{FC}=1.49 \pm 0.048$ ) (Pilowsky et al, $1992,1993)$. This suggests a high level of $D_{2}$ occupancy with risperidone.

We believe this to be the first example of a $D_{2}$ occupancy SPECT study for risperidone in a patient, and indeed in whom there was a definite clinical response. This is of relevance to understanding the drug's mechanism of action as it is difficult to predict its in vivo pharmacology from its experimental pharmacology. Our results suggest that in the therapeutic range the drug fully occupies $\mathrm{D}_{2}$ receptors. However, in classical terms it is an atypical antipsychotic since it is non-cataleptogenic. This supports the catalepsy test as a valuable screen for effective antipsychotics free from such side-effects without being hampered by presupposition about the mechanisms of action of a drug. Farde et al (1992) showed a threshold of $\mathrm{D}_{2}$ receptor occupancy of about $80 \%$ for the development of EPS. The occupancy of risperidone in this case was certainly higher but this patient was free from any side-effects.

The mechanism of this cannot be determined as yet, but clearly it is worth investigating the possibility that $5 \mathrm{HT}_{2}$ blockade protects against the provocation of EPS induced by high $\mathrm{D}_{2}$ occupancy. The role of $5 \mathrm{HT}_{2}$ blockade in this drug's action requires full clarification.

G. F. Busatto is sponsored by the CNPq (Brazil). L. S. Pilowsky is a Wellcome Research Training Fellow.

FArde, L., Norstrom, A.-L., Wiesel, F.-A., et al (1992) Positron emission tomographic analysis of central $D_{1}$ and $D_{2}$ dopamine receptor occupancy in patients treated with classical neuroleptics and clozapine: relation to extrapyramidal side effects. Archives of General Psychiatry. 49, 589-599.

LeYSEN, J. E., JANSSEN, P. M. F., GOMmeren, W., et al (1993) In vitro and in vivo receptor binding and monoamine turnover in rat brain regions of the novel antipsychotics. Molecular Pharmacology (in press).

Livingston, M. G., LOWE, M. R. \& TURNER, S. W. (1991) Risperidone ( $R 64766$ ) in acute episodes of schizophrenia: an open pilot dose-escalating study. Janssen Research Foundation, Clinical Research Report RIS 9BR 9003, N85-328.

Nyberg, S., FARde, L., Eriksson, L., et al (1993) 5HT $_{2}$ and $\mathrm{D}_{2}$ dopamine receptor occupancy in the living human brain. Psychopharmacology, 110, 265-272.

OVERALL, J. E. \& GORHAM, D. R. (1962) The brief psychiatric rating scale. Psychological Reports, 10, 799-812.

Pilowsky, L. S., Costa, D. C., Ell, P. J., et al (1992) Clozapine, single photon emission tomography and the $D_{2}$ dopamine receptor blockade hypothesis of schizophrenia. Lancet, 340, 199-202.

- - - - et al (1993) Antipsychotic medication, $D_{2}$ dopamine receptor blockade and clinical response: a ${ }^{123}$ I-IBZM SPET study. Psychological Medicine, 23, 791-799.
Wojcik, J. D., Gelenberg, A. J. \& LAbrie, R. A., et al (1980) Prevalence of tardive dyskinesia in an outpatient population. Comprehensive Psychiatry, 21, 370-380.

R. W. KERWIN

G. F. BuSATTO

L. S. PILOWSKY

Institute of Psychiatry

De Crespigny Park

Denmark Hill

London SE5 8AF

P. J. ELL

Institute of Nuclear Medicine

D. C. Costa

University College and Middlesex School of Medicine

London

N. P. L. G. VERHOEFF

Amsterdam Medical Centre and Cygne b.v.

Eidhoven University

The Netherlands

\section{Alcoholics with eating disorders}

SIR: Higuchi et al (Journal, March 1993, 162, 403-406) conclude that there is an association between eating disorder and alcohol abuse in women, but not in men. It would be dangerous to assume that the two conditions never co-exist in men and I would like to illustrate this by describing a case seen on our unit.

The eating disorder and alcohol abuse seem to have developed concurrently when he was aged 18 , but whereas the patient had received treatment on a number of occasions of his alcohol problem, his eating disorder had gone unrecognised for many years.

Case report. C, a 43-year-old man, was admitted electively to the regional addiction unit for alcohol detoxification and to the in-patient abstinence group. He had been assessed as an out-patient, and routine blood tests before admission had revealed a potassium concentration of $2.1 \mathrm{mM} / 1$. His general practitioner had prescribed him potassium supplements. He gave a 25-year history of heavy drinking (12 units or more per day) with a 10-year history of alcohol dependence syndrome. On admission he complained of depressed mood, with diurnal variation, initial insomnia and lethargy. He denied any vomiting or diarrhoea and no obvious case could be found for his hypokalemia.

He had a psychiatric history and had been admitted on at least five occasions to his local psychiatric hospital for treatment of depression and alcoholism. There was no other significant medical history.

He was a slim man, looking rather older than his years, with a plethoric complexion and swollen face. He was clinically depressed. Physical examination was essentially normal other than hepatomegaly and poor dental hygiene. 
He was commenced on an alcohol detoxification regime and further investigation of his hypokalaemia was attempted. During the course of his admission he confided to a member of staff that he had been vomiting on an almost daily basis for 25 years, following criticism of his weight by his father. He admitted bingeing (often daily), but denied the use of diuretics or laxatives.

Following this he received some cognitive psychotherapy and his depressive symptoms were treated with a serotoninspecific reuptake inhibitor antidepressant. On this regime his depressive and bulimic symptoms improved dramatically. His clinical chemistry returned to normal.

Regional Addiction Unit

KAREN WilliamS

All Saints Hospital

Lodge Road

Birmingham B18 5SD

\section{Anorexia nervosa: forced feeding and the law}

SIR: In their recent article about compulsory treatment for anorexia nervosa (Journal, May 1993, 162 679-680), Drs Tiller et al seem to assume that forced feeding under Section 3 of the Mental Health Act (MHA) 1983 is legal. We found that the law on this matter is by no means straightforward.

The patient, a 29-year-old woman, once a successful professional, lived at home with her elderly parents. She was diagnosed as having anorexia nervosa five years ago and did not respond to attempts to help her, never engaging with treatment offered by a variety of specialists in eating disorders. When her weight was $28 \mathrm{~kg}$, while in a medical ward, the consultant psychiatrist successfully recommended treatment under Section 3 of the MHA 1983. She offered little resistance to the insertion of a nasogastric tube, to taking chlorpromazine $(100 \mathrm{mg}$, daily), and to a carefully planned re-feeding programme. When she attained a weight of $32 \mathrm{~kg}$ the tube was withdrawn and she was transferred to the relatively comfortable psychiatric ward. However, her condition deteriorated once again and forced feeding needed to be reinstated.

The Court's inherent prerogative power to act on behalf of incapacitated adults was extinguished by statute in the UK in 1959. Although the common law has evolved to plug this gap, its powers are limited to making declarations of legality in individual cases, offering general guidelines and suggesting procedural steps to be followed (Lancet, 1993). There is a current lacuna in case law concerning adult anorexics refusing treatment ( $\operatorname{Re} \mathrm{T}$ (Adult) Refusal of Medical Treatment (1992, 4 All ER, 649)).

As the patient was refusing the insertion of a nasogastric tube, the hospital applied for two declarations. The first concerned the giving of treatment by way of artificial feeding as being lawful treatment. The second, that it was lawful treatment within Section 63 of the MHA 1983. Our medical opinion was that the patient did not have the capacity to consent as she seemed unable to appreciate the consequences of further starvation.

The judge ruled that the hospital was entitled to both declarations that it had sought. The patient was considered to lack the capacity to consent. The judge specified that "on the evidence, anorexia nervosa was a mental illness and in those circumstances, provided the treatment that was asked for and which the patient was refusing was the treatment for the mental illness from which she suffered, then the hospital was entitled not only to the declaration they sought in common law but also to the declaration as to the effect of the evidence on the statute". He remarked, however, that had the patient made an advance directive about forced feeding, the outcome might have been different (Brahams, 1993).

The judge's opinion about forced feeding and Section 63 of the MHA 1983 was categorical. He clearly stated that on the evidence "there is no room for argument that the introduction and the maintenance of compulsory feeding does form part of the treatment of the mental illness of anorexia nervosa" and that the prerequisites of Section 63 were met in our case. He also quoted Section 145 of the MHA 1983; "Medical treatment includes nursing and also includes care, habilitation and rehabilitation under medical supervision."

The proceedings did not help the patient. They had eroded further the poor therapeutic relationship and she continues to struggle with her life-threatening condition.

\footnotetext{
LANCET (1993) Mental incapacity and medical treatment. Lancet, 341, 1123-1124.
}

Brahams, D. (1993) Medicine and the law. Lancet, 341, 1143-1144.

Broadgreen Hospital NHS Trust

Colin Lanceley

Thomas Drive

Liverpool L14 3 LB

Scott Clinic

RAY TRAVERS

Rainhill Road

St Helens

\section{Panic disorder with agoraphobia}

SIR: Lelliott \& Marks(1988) previously claimed there was "massive evidence" that "exposure" was a specifically effective intervention for the reduction of 